\title{
Article \\ The Effect of Dry Carbon Dioxide Bathing on Peripheral Blood Circulation Measured by Thermal Imaging among Patients with Risk Factors of PAD
}

\author{
Hanna Zbroja *(D), Mateusz Kowalski and Anna Lubkowska (D) \\ Department of Functional Diagnostics and Physical Medicine, Faculty of Health Sciences, \\ Pomeranian Medical University in Szczecin, 71-210 Szczecin, Poland; mateuszk888@gmail.com (M.K.); \\ annalubkowska@gmail.com (A.L.) \\ * Correspondence: h.a.juchniewicz@gmail.com
}

Citation: Zbroja, H.; Kowalski, M.; Lubkowska, A. The Effect of Dry

Carbon Dioxide Bathing on Peripheral Blood Circulation Measured by Thermal Imaging among Patients with Risk Factors of PAD. Int. J. Environ. Res. Public Health 2021, 18, 1490. https://doi.org/ 10.3390/ijerph18041490

Academic Editor: Paul B.Tchounwou Received: 22 December 2020

Accepted: 31 January 2021

Published: 4 February 2021

Publisher's Note: MDPI stays neutral with regard to jurisdictional claims in published maps and institutional affiliations.

Copyright: (c) 2021 by the authors. Licensee MDPI, Basel, Switzerland. This article is an open access article distributed under the terms and conditions of the Creative Commons Attribution (CC BY) license (https:// creativecommons.org/licenses/by/ $4.0 /)$.

\begin{abstract}
Peripheral artery disease (PAD) is becoming a serious health problem of present times. It appears crucial to explore therapies that might help to restore blood flow or increase tissue oxygenation. The most effective methods of detecting early-stage changes in blood circulation in the extremities need to be identified. The aim of this study was to identify the effect of carbon dioxide $\left(\mathrm{CO}_{2}\right)$ bathing on peripheral blood circulation measured by thermal imaging among patients with risk factors of PAD and ankle-brachial index (ABI) in the normal range or $\mathrm{ABI}$ indicating some or moderate arterial disease (ABI $>0.5)$. The correlation between surface temperature change and PAD-relevant characteristics was also examined. Forty-six patients who were over 65 years old who had a minimum of two additional PAD risk factors were recruited. A series of ten dry $\mathrm{CO}_{2}$ baths was performed. Thermal images were taken before and after the intervention. The $\mathrm{CO}_{2}$ therapy caused a significant change in the body surface temperature of many body areas. Numerous moderate correlations between temperature change and health-related characteristics were identified. Therefore, patients with PAD risk factors could benefit from $\mathrm{CO}_{2}$ therapy. Improvements in blood flow change the body surface temperature, and these changes could be successfully detected by thermal imaging.
\end{abstract}

Keywords: carbon dioxide; cardiovascular disease; peripheral artery disease; therapy; thermography

\section{Introduction}

Peripheral artery disease (PAD) is becoming a serious health problem of present times. It is the third most common cardiovascular disease after coronary blood vessel disorders and stroke [1]. Among cardiovascular deaths, heart attack and stroke account for $85 \%$ of fatalities. The age-standardized rate (per 100,000) of deaths caused by cardiovascular diseases is $15,616.1$, while for PAD, it is 49.8 . Peripheral arterial disease is a failure of the proper functioning of arteries outside of the heart and brain. As a result, a reduction of blood circulation occurs in the human body, particularly in the extremities. PAD is most commonly caused by atherosclerosis, where a plaque causes narrowing or obstruction of the arteries. Most PAD patients are asymptomatic, but at the same time, many of them experience intermittent claudication (pain during walking) [2]. Critical limb ischemia occurs when the reduction in blood flow is severe enough to cause pain while resting or to cause tissue atrophy. Peripheral arterial disease is so dangerous that $10-15 \%$ of patients with intermittent claudication die within five years of diagnosis [3]. While the cardiovascular disease may not be the main cause of death of these patients, PAD might trigger several health complications that significantly shorten the lifespan of PAD patients. Therefore, it appears crucial to explore therapies that may help to restore blood flow or increase tissue oxygenation.

Carbon dioxide $\left(\mathrm{CO}_{2}\right)$ bathing has been shown to be effective in the treatment of peripheral vascular disorders. The effect of the percutaneous application of $\mathrm{CO}_{2}$ has been 
broadly studied. Carbon dioxide bath effectiveness is based on the fact that carbon dioxide acts as a vasodilator of blood vessels. Vasodilation properties of $\mathrm{CO}_{2}$ bathing have been proven by the study examining laser Doppler flux in cutaneous microcirculation in a group of young, healthy participants [4]. After a 35-min $\mathrm{CO}_{2}$ therapy, a significant increase in the extremities blood flow has been observed. Intracorporeal variations in $\mathrm{CO}_{2}$ concentrations affect both blood flow and the capacity of hemoglobin to release oxygen [5]. Carbon dioxide therapy has been proven to be effective in diminishing hypoxia-related damage, as it causes a significant increase in tissue oxygenation. The other controlled clinical trial with peripheral occlusive arterial disease patients provided proof that $\mathrm{CO}_{2}$ bath has a positive effect, reducing free radical plasma levels and increasing antioxidant levels [6]. It has been concluded that $\mathrm{CO}_{2}$ baths result in an improvement in microcirculation. Furthermore, a series of everyday $\mathrm{CO}_{2}$ baths over four weeks has resulted in elevated arterial peak flow, increased transcutaneous oxygen tension and most importantly longer pain-free walking distance among peripheral occlusive arterial disease patients [7]. This shows that $\mathrm{CO}_{2}$ baths can be a clinically effective treatment for PAD patients. The other clinically important result of $\mathrm{CO}_{2}$ baths was observed among patients with critical limb ischemia with ulceration or gangrene [8]. After $\mathrm{CO}_{2}$ bathing (10 min twice a day for 2 months), $83.1 \%$ of limbs became salvageable, and in as many as $96.4 \%$ of limbs, there was a reduction of ulcer or gangrene area to only one toe. Taking all the above evidence together, carbon dioxide bathing appears to be a very promising therapy for peripheral arterial disease patients. Therefore, research should focus on identifying the most effective methods of detecting early stage changes in blood circulation in the extremities, so that preventive therapies could be implemented.

Thermal imaging is a non-invasive, diagnostic imaging method [9]. It uses the measurement of medium and long waves of infrared radiation, which are emitted by any object/body whose temperature is above the absolute zero temperature [10]. The recorded wavelength is converted into temperature and presented visually as a thermograph/ thermogram [9]. Specialized software generating a thermal image allows assessment of the surface temperature of both the entire body and region of interest (ROI) [11]. Thermal imaging methods of skin temperature assessment in real time are characterized by measurement accuracy (up to $1 \%$ ), non-invasiveness, high sensitivity (up to $0.025^{\circ} \mathrm{C}$ ) and do not require direct physical contact with the patient [12].

Thanks to its properties, thermal imaging measurements are increasingly used in medicine to assess: the effect of cryotherapy, prevention and treatment of sports injuries, brown adipose tissue activity, surface temperature, metabolic disorders and temperature anomalies, inflammation, tumors, the effect of physical activity on temperature or as a method diagnostic of vascular diseases [11,13]. The wide application of thermal imaging in the diagnosis of disorders based on the analysis of the surface temperature of the skin $\left(\mathrm{T}_{\mathrm{SK}}\right)$ results from factors influencing its regulation. According to scientific reports, the regulation of skin temperature depends on blood pressure, the amount of subcutaneous tissue, the activity of the autonomic nervous system, and metabolism [12,14]. According to the studies by Lahiri [15] and Ring and Ammer [16], the clinical abnormality and the occurrence of disorders are reflected in an increased or decreased blood flow, which will directly increase or decrease the surface temperature of the skin.

Blood flow through the blood vessels (arteries and veins) is determined by the difference in systolic and diastolic vascular pressure and factors, which will affect the diameter of the blood vessel [17]. These factors include, among others, atherosclerosis [18]. Peripheral arterial disease may be asymptomatic in approximately $40 \%$ of patients [19], or it may cause coldness of the lower limbs, exertional pain, which may also appear at a later stage at rest, changes in skin color, and numbness [20]. The ankle-brachial index (ABI) is very often used to diagnose PAD. An ankle-brachial ratio above 0.9 indicates normal blood supply, while $\mathrm{ABI}<0.9$ indicates clinical signs of circulatory impairment, including $\mathrm{ABI}<0.4$ is critical ischemia. ABI has been shown to have high specificity $(85.7 \%)$ and sensitivity $(85.3 \%)$ for identifying PAD [21,22]. 
Due to the consequences of PAD and the frequent symptoms of this disease, i.e., coldness of the lower extremities, the use of thermal imaging seems to be a justified management procedure in this disease, as it not only assesses the initial condition of the patient, but also allows to monitor the progress of treatment [20].

In the current literature, the effectiveness of $\mathrm{CO}_{2}$ therapy among patients with moderate and severe arterial disease is frequently assessed. However, there is a lack of evidence regarding the effectiveness of $\mathrm{CO}_{2}$ therapy among patients with risk factors for PAD, yet their $\mathrm{ABI}$ is in the normal range or indicating only some arterial disease. The aim of this study is to identify the effect of carbon dioxide bathing on peripheral blood circulation measured by thermal imaging among patients with risk factors of PAD and ABI in normal range or ABI indicating some or moderate arterial disease. The secondary purpose of this study is to examine correlation between surface temperature change and PAD-relevant characteristics.

\section{Materials and Methods}

The study was approved by the Ethics Committee of the Pomeranian Medical University in Szczecin, Poland (KB-0012/16/17). This was a double-blinded randomized control trial. Recruitment for the study was carried out at the healthcare facilities in Szczecin. The information was promoted by posters and leaflets. The number of participants in each study group was based on the number of available volunteers, who expressed interest in participating in the trial.

Inclusion criteria were as follows:

- Written consent of the patients to participate in the study;

- Over 65 year of age;

- Minimum of additional two PAD risk factors among smoking, diabetes mellitus, hypertension, dyslipidemia, elevated C-reactive protein (CRP), hyperviscosity or hypercoagulable state, hyperhomocysteinemia, chronic renal insufficiency.

Peripheral arterial disease risk factors were defined according to the following criteria:

- Smoking-habit present or not (according to the patient-filled questionnaire);

- Diabetes mellitus-previously diagnosed diabetes mellitus, use of diabetic drug or fasting plasma glucose $\geq 126 \mathrm{mg} / \mathrm{dL}$;

- Hypertension - previously diagnosed hypertension, use of blood pressure-lowering drug or systolic blood pressure $\geq 140 \mathrm{mmHg}$ and/or diastolic blood pressure $\geq 90 \mathrm{mmHg}$;

- Dyslipidemia - previously diagnosed hypertension, use of a lipid-lowering drug, or any one of the following: total cholesterol level $\geq 240 \mathrm{mg} / \mathrm{dL}$, triglyceride level $\geq 150 \mathrm{mg} / \mathrm{dL}$, low-density-lipoprotein (LDL) cholesterol level $\geq 140 \mathrm{mg} / \mathrm{dL}$, high-density-lipoprotein (HDL) cholesterol level $<40 \mathrm{mg} / \mathrm{dL}$;

- $\quad$ Elevated c-reactive protein-CRP $>3.0 \mathrm{mg} / \mathrm{L}$;

- Hyperviscosity or hypercoagulable state-previously diagnosed hyperviscosity or hypercoagulable state;

- Hyperhomocysteinemia-blood homocysteine concentration $>15 \mu \mathrm{mol} / \mathrm{l}$; chronic renal insufficiency - previously diagnosed chronic renal insufficiency.

Exclusion criteria were as follows:

- Severe arterial disease defined by ankle-brachial index $<0.5$;

- Diagnosis of Buerger's disease;

- Current chemotherapy or radiotherapy;

- Current therapy with any immunosuppressive agent;

- Planned amputation within 6 months;

- Concurrent participation in another clinical study.

All the tests were performed at the Department of Functional Diagnostics and Physical Medicine at the Pomeranian Medical University in Szczecin, Poland. The study design is presented in Figure 1. All the participants were asked to fill in a socioeconomic form. The anthropometric measurements were performed, blood pressure and ABI (using MESI ABPI 
MD) were measured. The blood tests were also performed in order to identify parameters as follows: fasting glucose, glycated hemoglobin, total cholesterol, HDL cholesterol, LDL cholesterol, triglycerides, C-reactive protein, and homocysteine.

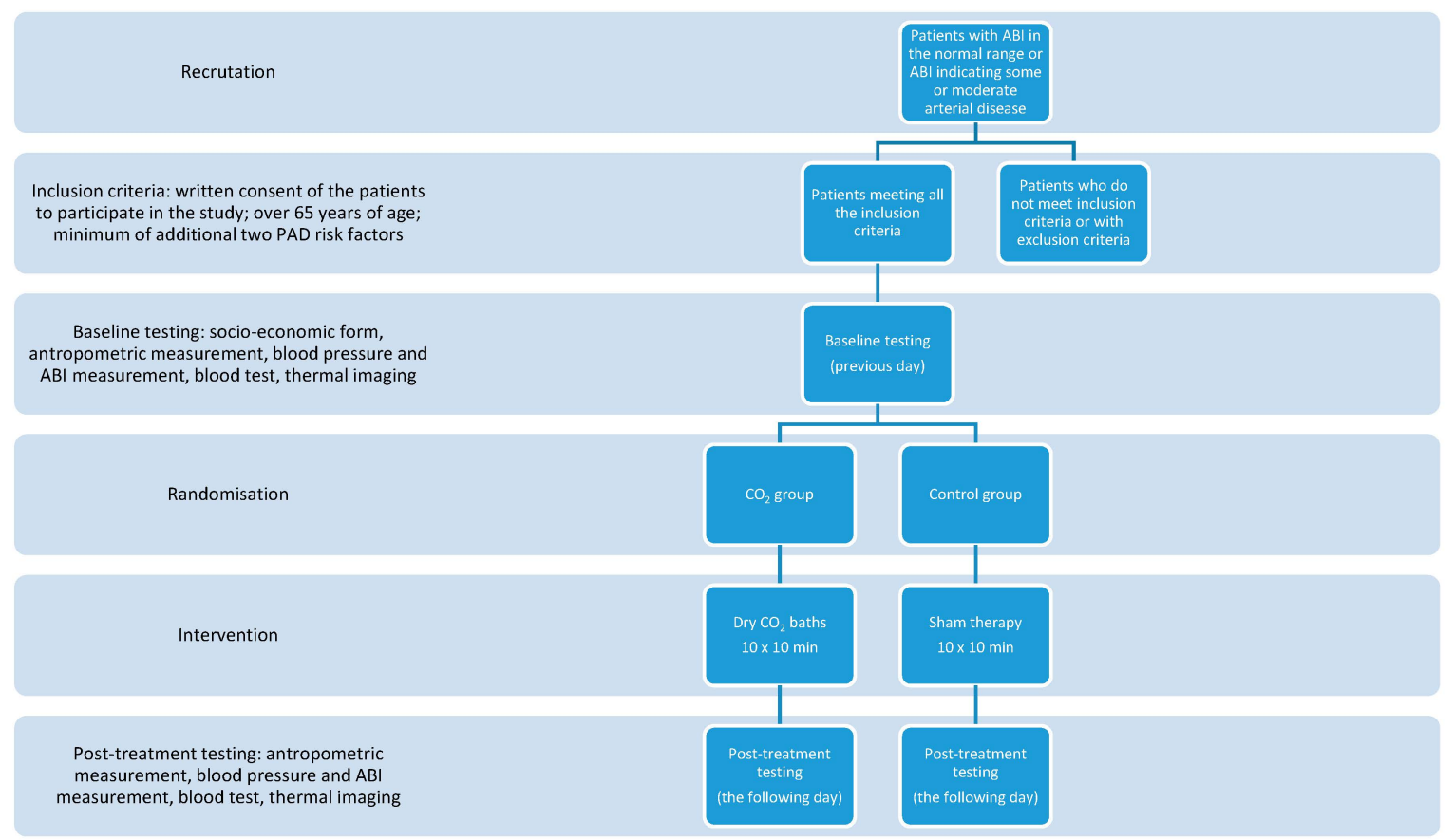

Figure 1. Study design.

All the participants were randomly assigned to one of two groups: control group (sham therapy) or $\mathrm{CO}_{2}$ group (participants were taking a dry $\mathrm{CO}_{2}$ bath). The randomization was based on a random number generation using a computer software program. Baths were performed using a MAXimus TOWER MX-1 device (MAXimus, Szczecin, Poland). The device allows for whole-body exposure (excluding the head). During the bath, a participant was sitting in the sealed chamber (neck and head stayed outside of the chamber). In the $\mathrm{CO}_{2}$ group, the $\mathrm{CO}_{2}$ gas was introduced into the chamber and automatically kept at the required concentration. In the sham, group $\mathrm{CO}_{2}$ was not introduced. For a better gas exposure patients were asked to take baths in their underwear. The duration of a single bath was $10 \mathrm{~min}$. A series of 10 treatments was performed over 12 day (five consecutive days, two days off, five consecutive days). The duration of a single bath, as well as the number of treatments was chosen in accordance with the Polish health system guidelines for the dry $\mathrm{CO}_{2}$ bathing therapy.

\subsection{Thermal Imaging Measurements}

Thermal images were taken one day before a series of $\mathrm{CO}_{2}$ baths and one day after the entire series of treatments has finished. A FLIR T103sc HD camera was used for the tests. This camera uses a detector with a resolution of $024 \times 768$. The thermal sensitivity of the camera is $<0.02 \mathrm{~K}$. All the photos were taken in accordance with the guidelines of the European Thermographic Society. Before taking the picture, the patients acclimatized to the conditions in the room for $10 \mathrm{~min}$. The acclimatization time was measured from the moment the outerwear was removed. During the test, the room temperature was monitored, which was $25^{\circ} \mathrm{C}$, and the air humidity was $50-55 \%$.

In order to obtain reliable, consistent and reproducible results, the TISEM questionnaire was used in the study, the guidelines of which were refined based on studies using thermal imaging [23].

All the participants were subjected to four thermal images in anatomical position in anterior-posterior projections (A-P): 
- Frontal plane front upper body;

- Frontal plane front lower body;

- Frontal plane back upper body;

- Frontal plane back lower body.

The following regions of interest were selected for detailed thermal imaging analysis:

- $\quad$ Upper back (UB);

- $\quad$ Lower back (LB);

- $\quad$ Chest $(\mathrm{CH})$;

- $\quad$ Abdomen $(\mathrm{AB})$;

- Upper limb (UL);

- Lower limb (LL).

Additionally, when assessing the distribution of the body surface temperature on the limbs, the following areas were selected for the upper limb (UL):

- $\quad$ arm anterior right $\left(\mathrm{AA}_{\mathrm{R}}\right)$;

- Arm anterior left $\left(\mathrm{AA}_{\mathrm{L}}\right)$;

- Forearm anterior right $\left(\mathrm{FRA}_{\mathrm{R}}\right)$;

- Forearm anterior left $\left(\mathrm{FRA}_{\mathrm{L}}\right)$;

- Hand palmar right $\left(\mathrm{HP}_{\mathrm{R}}\right)$;

- Hand palmar left $\left(\mathrm{HP}_{\mathrm{L}}\right)$;

- Arm posterior right $\left(\mathrm{AP}_{\mathrm{R}}\right)$;

- Arm posterior left $\left(\mathrm{AP}_{\mathrm{L}}\right)$;

- Forearm posterior right $\left(\mathrm{FRP}_{\mathrm{R}}\right)$;

- Forearm posterior left $\left(\mathrm{FRP}_{\mathrm{L}}\right)$;

- Hand dorsal right $\left(\mathrm{HD}_{\mathrm{R}}\right)$;

- Hand dorsal left $\left(\mathrm{HD}_{\mathrm{L}}\right)$.

Lower limb areas:

- Thigh anterior right $\left(\mathrm{TA}_{\mathrm{R}}\right)$;

- Thigh anterior left $\left(\mathrm{TA}_{\mathrm{L}}\right)$;

- $\quad$ Leg anterior right $\left(\mathrm{LA}_{\mathrm{R}}\right)$;

- Leg anterior left $\left(\mathrm{LA}_{\mathrm{L}}\right)$;

- Thigh posterior right $\left(\mathrm{TP}_{\mathrm{R}}\right)$;

- $\quad$ Thigh posterior left $\left(\mathrm{TP}_{\mathrm{L}}\right)$;

- Leg posterior right $\left(\mathrm{LP}_{\mathrm{R}}\right)$;

- Leg posterior left $\left(\mathrm{LP}_{\mathrm{L}}\right)$.

Each photo taken was saved in a digital form. The FLIR TOOLS program was used for a detailed analysis of the surface temperature distribution. Thanks to it, it was possible to designate symmetrical areas on the body and to compare the obtained results. For each area designated, the program determined the minimum temperature $\left(T_{\min }\right)$, the maximum temperature $\left(\mathrm{T}_{\text {maks }}\right)$ and the average temperature $\left(\mathrm{T}_{\text {mean }}\right)$. The mean temperature $\left(\mathrm{T}_{\text {mean }}\right)$ was used to analyze the results of surface temperature distribution in a given region of interest.

\subsection{Statistical Analysis}

The R-Studio program was used for statistical analysis. The normality of the distribution of the analyzed parameters was determined using the Anderson-Darling test. On its basis, the parametric $t$-test and the nonparametric Wilcoxon test were used for further analyses. A statistical significance level of $p<0.05$ was adopted for the above statistical analyses.

\section{Results}

The characteristics of 46 participants are presented in Table 1. There was no significant difference between two baseline study groups in any of the measured parameters. The mean age of participants was 71.7 year. Most of the participants were non-smokers 
or ex-smokers. Among current smokers, the range of smoked cigarettes was from 5 to 40 cigarettes per day. Mean body mass index (BMI) of the group indicates obesity. As many as 26 participants had BMI above $30 \mathrm{~kg} / \mathrm{m}^{2}$, while 17 subjects were overweight (BMI $\geq 25 \mathrm{~kg} / \mathrm{m}^{2}$ ) and only 10 participants had BMI within a normal range. There were no underweight participants (BMI $\leq 18.5 \mathrm{~kg} / \mathrm{m}^{2}$ ). Among modifiable PAD risk factors, hypertension and dyslipidemia were the most prevalent. Diabetes mellitus was also considerably prevalent. There was no person with chronic renal insufficiency.

Table 1. Population characteristics.

\begin{tabular}{cc}
\hline \multicolumn{1}{c}{ Population Characteristics } & \\
\hline Age, years & $n=46$ \\
Male: female sex ratio & $71.7( \pm 4.95)$ \\
White ethnicity, $n(\%)$ & $30: 70$ \\
Smoking status, $n(\%)$ & $46(100)$ \\
Current smoker & $5(10.9)$ \\
Ex-smoker & $18(39.1)$ \\
Non-smoker & $23(50.0)$ \\
body mass index, kg/m $\mathrm{m}^{2}$ & $30.1( \pm 5.9)$ \\
Hypertension, $n(\%)$ & $46(100.0)$ \\
Diabetes mellitus, $n(\%)$ & $34(73.9)$ \\
Dyslipidemia, $n(\%)$ & $43(93.5)$ \\
Hyperviscosity or hypercoagulable state, $n(\%)$ & $5(10.9)$ \\
Elevated inflammation markers, $n(\%)$ & $5(10.9)$ \\
Hyperhomocysteinemia, $n(\%)$ & $6(13.0)$ \\
Chronic renal insufficiency, $n(\%)$ & $0(0.0)$ \\
\hline
\end{tabular}

Unless otherwise stated, data are presented as mean (standard deviation).

Health-related characteristics of the study group are presented in Table 2. Among health-related characteristics, parameters indicating an increased risk for PAD development were examined. Mean waist-to-hip ratio indicates abdominal obesity among participants. Ankle-brachial index results are also presented in Table 2. Mean ABI was in a normal range for both study groups. One person had ABI above 1.4, which indicates stiffness or calcification of the blood vessels. Eight participants had ABI below 0.9 indicating some arterial disease. The therapy did not trigger improvement in the health-related characteristics. None of the parameters reached the statistically significant change. This is true for both study groups. Post-therapy ABI was also statistically the same as the baseline one.

Furthermore, the effect of dry $\mathrm{CO}_{2}$ bathing on body surface temperature was examined (Table 3). Statistical analysis revealed significant change in body surface temperature of leg anterior right and leg posterior right area following the sham therapy. The rest of the regions of interest showed no significant difference in surface body temperature following the sham therapy. The therapy of dry $\mathrm{CO}_{2}$ bathing resulted in a significant change of body surface temperature in the majority of the regions of interest, except for arm anterior left, arm anterior right, upper and lower back. In comparison to the control group, body surface temperature following the therapy among the participants of the $\mathrm{CO}_{2}$ group was also significantly different for the majority of the regions of interest, except for only the arm anterior right area.

In Tables 4 and 5, results of the correlation between the change of the surface temperature and health-related characteristics are presented for the control and the $\mathrm{CO}_{2}$ group, respectively. These tables present only statistically significant correlations. For the control group, negative correlations were observed between surface temperature change and body fat tissue, homocysteine, waist-to-hip ratio, as well as presence of hypertension and type 2 diabetes mellitus. What is interesting, in two regions of interest of participants in the control group, a positive correlation was identified between surface temperature change and total cholesterol. For the $\mathrm{CO}_{2}$ group, statistical analysis revealed a negative correlation 
between some regions of interest and CRP, fasting glucose and hypercholesterolemia state. On the other hand, a positive correlation was identified for systolic blood pressure and LDL-cholesterol. All the above correlations are moderate.

Table 2. Health-related characteristics.

\begin{tabular}{|c|c|c|c|c|c|c|}
\hline \multirow[t]{2}{*}{ Health-Related Characteristics } & \multicolumn{3}{|c|}{ Control Group } & \multicolumn{3}{|c|}{$\mathrm{CO}_{2}$ Group } \\
\hline & $\mathrm{T}_{0}$ & $\mathrm{~T}_{1}$ & $p$-Value & $\mathrm{T}_{0}$ & $\mathrm{~T}_{1}$ & $p$-Value \\
\hline \multicolumn{7}{|l|}{ Waist circumference, $\mathrm{cm}$} \\
\hline Men & $106.8( \pm 11.1)$ & $104.8( \pm 11.1)$ & 0.95 & $102.9( \pm 9.5)$ & $103.1( \pm 7.8)$ & 0.23 \\
\hline Women & $93.1( \pm 14.0)$ & $92.2( \pm 14.0)$ & 0.92 & $97.9( \pm 10.8)$ & $96.9( \pm 10.9)$ & 0.89 \\
\hline \multicolumn{7}{|l|}{ Waist-to-hip ratio } \\
\hline Men & $0.99( \pm 0.03)$ & $0.97( \pm 0.02)$ & 0.98 & $0.96( \pm 0.05)$ & $0.97( \pm 0.03)$ & 0.18 \\
\hline Women & $0.88( \pm 0.05)$ & $0.88( \pm 0.05)$ & 0.40 & $0.93( \pm 0.03)$ & $0.93( \pm 0.03)$ & 0.53 \\
\hline Ankle-brachial index & $1.1( \pm 0.2)$ & $1.1( \pm 0.2)$ & 0.91 & $1.0( \pm 0.2)$ & $1.0( \pm 0.2)$ & 0.86 \\
\hline Fasting glucose, (mg/dL) & $112.1( \pm 26.8)$ & $110.8( \pm 22.0)$ & 0.81 & $114.4( \pm 29.3)$ & $118.5( \pm 34.2)$ & 0.59 \\
\hline Glycated hemoglobin, $(\%)$ & $5.9( \pm 0.5)$ & $6.0( \pm 0.6)$ & 0.99 & $6.1( \pm 0.7)$ & $6.1( \pm 0.7)$ & 0.99 \\
\hline Total cholesterol, (mg/dL) & $184.7( \pm 43.3)$ & $184.0( \pm 37.1)$ & 0.98 & $180.5( \pm 41.0)$ & $174.6( \pm 39.8)$ & 0.98 \\
\hline LDL-cholesterol, (mg/dL) & $112.0( \pm 40.2)$ & $113.4( \pm 34.7)$ & 0.67 & $116.1( \pm 40.4)$ & $110.9( \pm 40.8)$ & 0.95 \\
\hline HDL-cholesterol, (mg/dL) & $62.0( \pm 16.1)$ & $60.5( \pm 16.1)$ & 1.00 & $52.3( \pm 13.3)$ & $53.5( \pm 12.4)$ & 1.00 \\
\hline Triglycerides, (mg/dL) & $135.2( \pm 67.9)$ & $133.0( \pm 68.4)$ & 0.98 & $166.7( \pm 102.4)$ & $135.5( \pm 66.6)$ & 0.99 \\
\hline C-reactive protein, $(\mathrm{mg} / \mathrm{L})$ & $2.5( \pm 2.1)$ & $3.0( \pm 3.6)$ & 0.79 & $2.6( \pm 1.8)$ & $4.1( \pm 4.4)$ & 0.99 \\
\hline Homocysteine, $(\mathrm{mol} / \mathrm{L})$ & $13.3( \pm 2.5)$ & $13.4( \pm 3.2)$ & 0.86 & $16.3( \pm 6.1)$ & $15.7( \pm 5.5)$ & 0.27 \\
\hline Systolic blood pressure, $(\mathrm{mmHg})$ & $140.0( \pm 22.0)$ & $139.7( \pm 22.7)$ & 0.28 & $157.8( \pm 23.3)$ & $153.5( \pm 19.4)$ & 0.99 \\
\hline Diastolic blood pressure, $(\mathrm{mmHg})$ & $72.2( \pm 10.6)$ & $72.2( \pm 10.8)$ & 0.84 & $79.4( \pm 11.6)$ & $80.0( \pm 10.5)$ & 0.79 \\
\hline
\end{tabular}

Unless otherwise stated, data are presented as mean (standard deviation). $p$-value was calculated by two-sample $t$-test and Wilcoxon signed-rank test. $\mathrm{T}_{0}-$ measurements taken before intervention; $\mathrm{T}_{1}-$ measurements taken after 10 sham or dry $\mathrm{CO}_{2}$ baths. HDL-highdensity-lipoprotein cholesterol; LDL-low-density-lipoprotein cholesterol. 
Table 3. Results of tests of statistical surface temperatures of selected region of interest (ROI) during $\mathrm{T}_{0}$ and $\mathrm{T}_{1}$ for the study group and the control group.

\begin{tabular}{|c|c|c|c|c|c|c|c|c|c|c|c|c|c|}
\hline \multicolumn{7}{|c|}{ Control Group } & \multicolumn{6}{|c|}{$\mathrm{CO}_{2}$ Group } & \multirow[t]{2}{*}{$p$-Value } \\
\hline & $\mathbf{T}$ & & $\mathbf{T}$ & & & & $\mathbf{T}$ & & $\mathrm{T}$ & & & & \\
\hline Region of interest & $\begin{array}{c}\bar{X} \text { temp. } \\
\left({ }^{\circ} \mathrm{C}\right)\end{array}$ & $\pm \mathrm{SD}$ & $\begin{array}{c}\bar{X} \text { temp. } \\
\left({ }^{\circ} \mathrm{C}\right)\end{array}$ & $\pm \mathrm{SD}$ & $\Delta \mathrm{T}$ & $\begin{array}{c}p \text {-value } \\
\mathrm{T}_{0} \text { vs. } \mathrm{T}_{1}\end{array}$ & $\begin{array}{c}\bar{X} \text { temp. } \\
\left({ }^{\circ} \mathrm{C}\right)\end{array}$ & $\pm \mathrm{SD}$ & $\begin{array}{c}\bar{X} \text { temp. } \\
\left({ }^{\circ} \mathrm{C}\right)\end{array}$ & $\pm \mathrm{SD}$ & $\Delta \mathrm{T}$ & $\begin{array}{c}p \text {-value } \\
\mathrm{T}_{0} \text { vs. } \mathrm{T}_{1}\end{array}$ & $\begin{array}{c}p \text {-value } \\
\mathrm{T}_{1} \text { placebo } \\
\text { vs. } \mathrm{T}_{1} \mathrm{CO}_{2}\end{array}$ \\
\hline Arm anterior right & 31.73 & 1.15 & 32.40 & 1.10 & -0.67 & 0.682 & 32.13 & 1.14 & 32.01 & 0.12 & 0.84 & 0.075 & 0.205 \\
\hline Forearm anterior right & 31.65 & 1.20 & 32.70 & 1.07 & -1.04 & 0.982 & 31.76 & 0.87 & 31.65 & 0.11 & 0.78 & 0.007 & 0.001 \\
\hline Hand palmar right & 28.71 & 2.91 & 31.79 & 1.51 & -3.08 & 0.288 & 29.47 & 3.14 & 28.54 & 0.93 & 2.70 & 0.001 & 0.001 \\
\hline Arm posterior right & 30.33 & 1.18 & 31.57 & 1.20 & -1.24 & 0.973 & 30.34 & 1.41 & 30.22 & 0.12 & 1.27 & 0.001 & 0.001 \\
\hline Forearm posterior right & 31.73 & 0.88 & 32.60 & 1.06 & -0.86 & 0.296 & 31.69 & 1.04 & 31.28 & 0.41 & 1.11 & 0.004 & 0.001 \\
\hline Hand dorsal right & 28.11 & 3.11 & 31.66 & 1.49 & -3.56 & 0.108 & 29.40 & 2.65 & 28.01 & 1.39 & 3.10 & 0.001 & 0.001 \\
\hline Arm anterior left & 31.85 & 1.27 & 32.57 & 1.17 & -0.73 & 0.766 & 31.88 & 0.83 & 31.87 & 0.01 & 0.68 & 0.076 & 0.044 \\
\hline Forearm anterior left & 31.75 & 1.21 & 32.73 & 1.16 & -0.97 & 0.394 & 31.79 & 0.88 & 31.58 & 0.21 & 0.76 & 0.015 & 0.001 \\
\hline Hand palmar left & 28.69 & 2.64 & 31.80 & 1.29 & -3.11 & 0.233 & 29.85 & 2.97 & 28.70 & 1.14 & 3.42 & 0.001 & 0.001 \\
\hline Arm posterior left & 30.17 & 1.21 & 31.43 & 1.06 & -1.25 & 0.860 & 30.24 & 1.34 & 30.17 & 0.07 & 1.27 & 0.001 & 0.002 \\
\hline Forearm posterior left & 31.65 & 1.19 & 32.56 & 1.30 & -0.91 & 0.242 & 31.43 & 0.90 & 31.10 & 0.33 & 0.98 & 0.030 & 0.001 \\
\hline Hand dorsal left & 28.31 & 2.63 & 31.31 & 1.50 & -3.00 & 0.371 & 28.97 & 3.31 & 28.16 & 0.80 & 2.70 & 0.001 & 0.001 \\
\hline Thigh anterior right & 30.04 & 1.29 & 32.08 & 1.27 & -2.04 & 0.511 & 30.43 & 1.23 & 30.20 & 0.23 & 1.12 & 0.001 & 0.001 \\
\hline Leg anterior right & 31.83 & 0.65 & 32.81 & 0.89 & -0.98 & 0.025 & 32.00 & 1.15 & 31.24 & 0.76 & 1.05 & 0.001 & 0.001 \\
\hline Thigh posterior right & 30.62 & 1.15 & 32.53 & 1.15 & -1.91 & 0.079 & 30.90 & 1.17 & 30.30 & 0.60 & 1.09 & 0.001 & 0.001 \\
\hline Leg posterior right & 31.01 & 0.78 & 32.28 & 0.75 & -1.27 & 0.046 & 31.10 & 1.08 & 30.53 & 0.57 & 0.76 & 0.001 & 0.001 \\
\hline Thigh anterior left & 30.24 & 1.65 & 32.13 & 1.30 & -1.88 & 0.408 & 30.28 & 1.20 & 30.00 & 0.28 & 1.09 & 0.001 & 0.001 \\
\hline Leg anterior left & 32.09 & 1.01 & 32.81 & 0.98 & -0.72 & 0.092 & 31.62 & 1.38 & 31.01 & 0.62 & 1.02 & 0.031 & 0.001 \\
\hline Thigh posterior left & 30.62 & 1.31 & 32.40 & 1.15 & -1.78 & 0.175 & 31.04 & 1.19 & 30.59 & 0.45 & 1.01 & 0.001 & 0.001 \\
\hline Leg posterior left & 31.11 & 0.67 & 32.25 & 0.77 & -1.14 & 0.197 & 30.98 & 1.13 & 30.60 & 0.38 & 0.82 & 0.001 & 0.001 \\
\hline Chest & 32.37 & 1.09 & 33.32 & 0.92 & -0.95 & 0.767 & 32.47 & 0.83 & 32.54 & -0.08 & 0.95 & 0.006 & 0.011 \\
\hline Abdomen & 31.72 & 1.40 & 32.79 & 1.19 & -1.07 & 0.272 & 31.60 & 1.10 & 31.24 & 0.36 & 1.08 & 0.015 & 0.001 \\
\hline Upper back & 32.39 & 1.27 & 33.03 & 1.05 & -0.63 & 0.775 & 32.40 & 1.00 & 32.32 & 0.08 & 0.79 & 0.103 & 0.034 \\
\hline Lower back & 31.93 & 1.38 & 32.59 & 1.40 & -0.66 & 0.507 & 31.93 & 1.18 & 31.71 & 0.21 & 0.97 & 0.214 & 0.022 \\
\hline
\end{tabular}

$p$-value was calculated by two-sample t-test and Wilcoxon signed-rank test; $\mathrm{T}_{0}$-measurements taken before intervention; $\mathrm{T}_{1}-$ measurements taken after 10 sham or dry $\mathrm{CO}_{2}$ baths;

$\Delta \mathrm{T}$-difference in the temperature between $\mathrm{T}_{0}$ and $\mathrm{T}_{1}$. 
Table 4. Statistical significance results in the control group at $\Delta \mathrm{T}$.

\begin{tabular}{ccccc}
\hline Variable & ROI & $p$-Value & Cor/Rho/tau & Correlation Type \\
\hline \multirow{2}{*}{ Total cholesterol } & $\mathrm{TP}_{\mathrm{L}}$ & 0.037 & 0.481 & Pearson's \\
Body fat & $\mathrm{LP}$ & 0.046 & 0.462 & Pearson's \\
Homocysteine & $\mathrm{LA}_{\mathrm{R}}$ & 0.022 & -0.523 & Pearson's \\
Waist-to-hip ratio & $\mathrm{AP}$ & 0.049 & -0.456 & Pearson's \\
Hypertension & $\mathrm{TP}_{\mathrm{R}}$ & 0.049 & -0.456 & Pearson's \\
& $\mathrm{HP}_{\mathrm{R}}$ & 0.039 & -0.408 & Kendall \\
Diabetes & $\mathrm{AP}_{\mathrm{R}}$ & 0.023 & -0.450 & Kendall \\
& $\mathrm{LA}_{\mathrm{R}}$ & 0.021 & -0.457 & Kendall \\
& $\mathrm{LP}_{\mathrm{L}}$ & 0.037 & -0.414 & Kendall \\
\hline
\end{tabular}

ROI-region of interest; Cor-Pearson's correlation coefficient; Rho-Spearman's correlation coefficient; tauKendall's correlation coefficient; $\mathrm{TP}_{\mathrm{L}}$-thigh posterior left; $\mathrm{LP}_{\mathrm{L}}$-leg posterior left; $\mathrm{LA}_{\mathrm{R}}$-leg anterior right. $\mathrm{AP}_{\mathrm{R}}$-arm posterior right; $\mathrm{TP}_{\mathrm{R}}$ 一thigh posterior right; $\mathrm{HP}_{\mathrm{R}}$ - hand palmar right.

Table 5. Results of statistical significance in the $\mathrm{CO}_{2}$ group at $\Delta \mathrm{T}$.

\begin{tabular}{ccccc}
\hline Variable & ROI & $p$-Value & Cor/Rho/tau & Correlation Type \\
\hline \multirow{2}{*}{ Systolic blood pressure } & $\mathrm{AA}_{\mathrm{R}}$ & 0.031 & 0.450 & Pearson's \\
CRP & $\mathrm{AB}$ & 0.022 & 0.475 & Pearson's \\
LDL-cholesterol & $\mathrm{TP}$ & 0.036 & -0.438 & Spearman \\
& $\mathrm{LA}$ & 0.015 & 0.500 & Pearson's \\
\multirow{5}{*}{ Fasting glucose } & $\mathrm{TP}_{\mathrm{L}}$ & 0.034 & -0.446 & Spearman \\
& $\mathrm{TA}_{\mathrm{L}}$ & 0.048 & -0.416 & Spearman \\
& $\mathrm{TP}_{\mathrm{R}}$ & 0.039 & -0.433 & Spearman \\
& $\mathrm{HD}_{\mathrm{R}}$ & 0.034 & -0.442 & Spearman \\
\multirow{3}{*}{ Hypercholesterolemia } & $\mathrm{AP}_{\mathrm{R}}$ & 0.017 & -0.428 & Kendall \\
& $\mathrm{AP}_{\mathrm{L}}$ & 0.021 & -0.413 & Kendall \\
& $\mathrm{LA}$ & 0.025 & -0.402 & Kendall \\
& $\mathrm{LB}$ & 0.017 & -0.425 & Kendall \\
\hline
\end{tabular}

ROI-region of interest; Cor-Pearson's correlation coefficient; Rho-Spearman's correlation coefficient; tauKendall's correlation coefficient; CRP-C-reactive protein; LDL-low-density-lipoprotein cholesterol; $\mathrm{AA}_{\mathrm{R}}$-arm anterior right; $\mathrm{AB}$ - abdomen; $\mathrm{TP}_{\mathrm{L}}$ - thigh posterior left; $\mathrm{LA}_{\mathrm{R}}$-leg anterior right; $\mathrm{TP}_{\mathrm{L}}$ —thigh anterior left; $\mathrm{TA}_{\mathrm{L}}$ thigh anterior left; $\mathrm{TP}_{\mathrm{R}}$ 一thigh posterior right; $\mathrm{HD}_{\mathrm{R}}$ - hand dorsal right; $\mathrm{AP}_{\mathrm{R}}$-arm posterior right; $\mathrm{AP}_{\mathrm{L}}$-arm posterior left; LB-lower back.

\section{Discussion}

Cardiovascular diseases (CVD) are the leading cause of death globally [24]. Around 18 million people died from cardiovascular disease in 2016. The social and economic consequences of PAD need to be acknowledged. There is a great need for developing global prevention programs, as well as cost-effective treatments and management policies. Carbon dioxide bathing therapy has been proposed as one of the treatments that may bring health and quality of life-related benefits for patients with hypoxic syndromes and diabetes mellitus. The aim of this study was to identify the effect of carbon dioxide bathing on peripheral blood circulation measured by thermal imaging among patients with risk factors of PAD and ABI in the normal range or ABI indicating some or moderate arterial disease. The correlation between surface temperature change and PAD-relevant characteristics was also examined.

In this study, preventive therapy in the form of dry $\mathrm{CO}_{2}$ bathing did not cause a change in health-related characteristics. None of the PAD risk factors were improved. This may be explained by several factors. The size of the study group may be too small to show a significant change. Therefore, a need to perform similar interventions among a greater group of participants would be necessary. The second explanation is that the number of dry baths could be too low to trigger a significant change in health-related characteristics. The reason for choosing only ten dry $\mathrm{CO}_{2}$ baths was based on the fact that this is the most prevalent therapy length in the Polish health system. The aim of this study was to examine the effectiveness of the therapy with parameters that are broadly used. The lack of 
improvement in PAD risk factors indicates a great need for a revision of guidelines for the length of dry $\mathrm{CO}_{2}$ bathing therapy.

The main finding of this study is that dry $\mathrm{CO}_{2}$ bathing caused a significant change in body surface temperature of lower extremities, as well as in many other body areas. Furthermore, a moderate negative correlation between some regions of interest temperature change caused by dry $\mathrm{CO}_{2}$ baths and health-related characteristics, such as CRP, fasting glucose and hypercholesterolemia state, was identified. The negative correlation may be explained by the fact that people with more advanced risk factors achieve smaller benefits from $\mathrm{CO}_{2}$ baths. On the other hand, a moderate positive correlation was observed for systolic blood pressure and LDL-cholesterol. Therefore, higher LDL-cholesterol or systolic blood pressure is correlated with a greater change in the leg surface temperature. These results suggest that PAD patients with elevated systolic blood pressure and LDL-cholesterol may be better responders for the $\mathrm{CO}_{2}$ bathing therapy. Overall, these results suggest that patients with risk factors of PAD and $\mathrm{ABI}$ in the normal range or ABI indicating some or moderate arterial disease can benefit from the $\mathrm{CO}_{2}$ bathing therapy. These health improvements result in better circulation that could be successfully observed by thermal imaging.

In the current literature, there are studies supporting our results. The attempt to detect the early stages of foot ulcers among diabetes patients has been done with the thermal imaging method [25]. The temperature of corresponding areas of the right and left feet does not usually differ more than $1{ }^{\circ} \mathrm{C}$ in the diabetic foot. In contrast, values for temperature differentials above $2.2^{\circ} \mathrm{C}$ indicate possible hyperthermia. In this study, nine out of 85 images have shown hyperthermia areas greater than $1 \mathrm{~cm}$. It has been suggested that this temperature difference may indicate an early stage of ulcer development. However, a prospective study has not been done, and the real clinical significance of these findings is not known.

Similarly, a pilot study among 15 diabetic patients had also the aim of exploring the first signs of diabetic foot disease by high-resolution infrared thermal imaging [26]. However, in this study, the thermal imaging effectiveness in detecting signs of foot ulcers can be assessed, as patients were divided into three groups: patients without present signs of diabetic foot complications, patients with local signs of diabetic foot complications, and patients with diffuse complications. Results revealed that the difference in mean temperature between feet of patients with no complication was at a maximum of $1.5^{\circ} \mathrm{C}$, while for patients with diffuse complication, this difference was at a minimum of $3{ }^{\circ} \mathrm{C}$. Thermal imaging showed that feet with osteomyelitis or Charcot feet are warmer, while feet with critical ischemia were colder compared with the contralateral foot. These results indicate that infrared thermal imaging may be appropriate as a diagnostic tool for the detection of signs of diabetic foot disease. From this study, with the background of previously published literature, temperature difference thresholds for various diabetic foot complications can be drawn [27-29]. The temperature difference at the level of $2{ }^{\circ} \mathrm{C}$ corresponds to neuropathic ulcers, abundant callus, while $3{ }^{\circ} \mathrm{C}$ or more indicates Charcot foot, ulcers with osteomyelitis, as well as critical ischemia.

Most importantly, the thermal imaging method may provide clinically important prevention. A randomized controlled trial lasting for 18 months and involving 225 diabetic patients at high-risk for ulceration was testing the effectiveness of home-based foot skin temperature monitoring in terms of ulcer prevention [27]. Proportional hazard regression analysis revealed that the control group had almost three times higher risk of shorter time to ulceration. Similar results have been achieved in smaller ( 85 diabetic patients) and shorter studies (6 months) with very similar intervention-home-based foot skin temperature monitoring, but in six (instead of one) predetermined sites of foot [28]. Foot skin temperature monitoring caused a significantly lower risk of diabetic foot complications ( $5 \%$ vs. $20 \%$ in the control group). Regular foot skin temperature monitoring results in faster detection of the problem and faster diagnosis of diabetic foot complications. Medical 
intervention at the time of early stage of developing complications proves to be more effective than treating late-stage diabetic foot complications.

However, studies can also be found that do not support the hypothesis of thermal imaging effectiveness in distinguishing blood flow. For example, a study examining 100 critically ill patients with vascular impairments has shown that patients with or without underlying vascular disease or low perfusion pressures may present with lowered relative sacral temperatures [30]. The purpose of this study was to identify those patients with significant vascular disease and the risk for pressure injury of the sacral area. Thirty-two patients showed temperature differentials that met or exceeded the $-1.5^{\circ} \mathrm{C}$ threshold between the sacral and the control areas. The average temperature differential was $-1.92{ }^{\circ} \mathrm{C} \pm 0.62{ }^{\circ} \mathrm{C}$. However, 6 patients had a temperature differential at the level of $+1.5^{\circ} \mathrm{C}$ or more. Various clinical subgroups were also assessed separately, and no relationship was found between temperature differentials and perfusion for patients with cardiovascular diseases nor patients with a mean blood pressure of less than $60 \mathrm{mmHg}$. No significant difference was also found among patients with a deep tissue pressure injury. Therefore, these results do not support the use of temperature differentials to detect patients at particularly high risk for pressure injury owing to local blood flow.

In order to further verify the clinical value of infrared thermal imaging, this method was compared with Doppler compression ultrasonography in terms of deep vein thrombosis [31]. The results revealed the sensitivity at the level of $88.3 \%$, the specificity of $65.0 \%$, and a diagnostic accordance rate of $75.0 \%$. Thermal imaging gave $11.7 \%$ of false-positive diagnosis and $35.0 \%$ of false-negative diagnosis. It was concluded that infrared thermal imaging could be used for detecting deep vein thrombosis and adjunctive diagnostic screening. The combination of thermal imaging and Doppler compression ultrasonography screening could be a high value for early-stage detection and definitive diagnosis of deep vein thrombosis.

One of the strengths of our study is the fact of automated image analysis. Most of the published literature is based on manual image analysis. The computer-based analysis provides higher accuracy, reliability and replicability. Infrared temperature measurements have some limitations as well. Foot temperature may vary from person to person as a result of age-, sex-, health-related differences, as well as environmental factors. A better-designed study could take into account intraindividual temperature patterns and changes prior to determining disease-related changes.

One of the limitations of this study is the lack of power calculation prior to the recruitment. The results obtained from this study confirmed a low statistical power at the level close to 0.3. In order to assess the number of participants needed to achieve significant change as a result of using dry $\mathrm{CO}_{2}$ baths, the sample size was estimated. On the basis of the results reflecting the change in average temperature values as a result of the $\mathrm{CO}_{2}$ baths, it was estimated that 100 study participants would be appropriate to have power at the level of 0.8 . The other limitation of our study may be the recruitment of patients with $\mathrm{ABI}$ within a normal range or $\mathrm{ABI}$ indicating some arterial disease.

\section{Conclusions}

On the basis of thermal imaging, this study suggests that patients with risk factors of PAD and $\mathrm{ABI}$ in the normal range or $\mathrm{ABI}$ indicating some or moderate arterial disease could benefit from dry $\mathrm{CO}_{2}$ bathing therapy. Improvements in blood flow change the body surface temperature, and these changes could be detected by thermal imaging. In order to reach a clinically significant change shown by the improvement in PAD risk factors parameters, more than ten dry $\mathrm{CO}_{2}$ baths are required, as evidenced by this study.

Author Contributions: Conceptualization. H.Z., M.K. and A.L.; methodology. H.Z., M.K. and A.L.; software. M.K.; validation. H.Z., M.K. and A.L.; formal analysis. H.Z., M.K. and A.L.; investigation. H.Z. and M.K.; resources. H.Z., M.K. and A.L.; data curation. H.Z. and M.K.; writing-original draft preparation. H.Z and M.K.; writing-review and editing. H.Z.; visualization. H.Z.; supervision. 
A.L.; project administration. A.L. All authors have read and agreed to the published version of the manuscript.

Funding: This research received no external funding.

Institutional Review Board Statement: The study was conducted according to the guidelines of the Declaration of Helsinki and approved by the Ethics Committee of the Pomeranian Medical University in Szczecin, Poland (KB-0012/16/17; date of approval: 16.01.2017).

Informed Consent Statement: Informed consent was obtained from all subjects involved in the study.

Data Availability Statement: The data presented in this study are available on request from the corresponding author.

Conflicts of Interest: The authors declare no conflicts of interest.

\section{References}

1. Fowkes, F.G.; Rudan, D.; Rudan, I.; Aboyans, V.; Denenberg, J.O.; McDermott, M.M.; Norman, P.E.; Sampson, U.K.; Williams, L.J.; Mensah, G.A.; et al. Comparison of global estimates of prevalence and risk factors for peripheral artery disease in 2000 and 2010 : A systematic review and analysis. Lancet 2013, 382, 1329-1340. [CrossRef]

2. Crawford, F.; Welch, K.; Andras, A.; Chappell, F.M. Ankle brachial index for the diagnosis of lower limb peripheral arterial disease. Cochrane Database Syst. Rev. 2016, 2016. [CrossRef] [PubMed]

3. Morley, R.L.; Sharma, A.; Horsch, A.D.; Hinchliffe, R.J. Peripheral Artery Disease. BMJ 2018, 374, 861-871. [CrossRef]

4. Finzgar, M.; Melik, Z.; Cankar, K. Effect of transcutaneous application of gaseous carbon dioxide on cutaneous microcirculation. Clin. Hemorheol. Microcirc. 2015, 60, 423-435. [CrossRef]

5. Brandi, C.; Grimaldi, L.; Nisi, G.; Brafa, A.; Campa, A.; Calabrò, M.; Campana, M.; D'Aniello, C. The role of carbon dioxide therapy in the treatment of chronic wounds. In Vivo 2010, 24, 223-226. [PubMed]

6. Dogliotti, G.; Galliera, E.; Iorio, E.; Valserra, M.D.B.D.; Solimene, U.; Corsi, M.M. Effect of immersion in $\mathrm{CO}_{2}$-enriched water on free radical release and total antioxidant status in peripheral arterial occlusive disease. Int. Angiol. 2011, 30, $12-17$.

7. Hartmann, B.R.; Bassenge, E.; Hartmann, M. Effects of Serial Percutaneous Application of Carbon Dioxide in Intermittent Claudication: Results of a Controlled Trial. Angiology 1997, 48, 957-963. [CrossRef] [PubMed]

8. Toriyama, T.; Kumada, Y.; Matsubara, T.; Murata, A.; Ogino, A.; Hayashi, H.; Nakashima, H.; Takahashi, H.; Matsuo, H.; Kawahara, H. Effect of artificial carbon dioxide foot bathing on critical limb ischemia (Fontaine IV) in peripheral arterial disease patients. Int. Angiol. 2002, 21, 367. [PubMed]

9. Tattersall, G.J. Infrared thermography: A non-invasive window into thermal physiology. Comp. Biochem. Physiol. Part A Mol. Integr. Physiol. 2016, 202, 78-98. [CrossRef]

10. Carpes, F.P.; Mello-Carpes, P.B.; Priego Quesada, J.I.; Pérez-Soriano, P.; Salvador Palmer, R.; Ortiz de Anda, R.M.C. Insights on the use of thermography in human physiology practical classes. Adv. Physiol. Educ. 2018, 42, 521-525. [CrossRef]

11. Moreira, D.G.; Costello, J.T.; Brito, C.J.; Adamczyk, J.G.; Ammer, K.; Bach, A.J.; Costa, C.M.; Eglin, C.; Fernandes, A.A.; FernándezCuevas, I.; et al. Thermographic imaging in sports and exercise medicine: A Delphi study and consensus statement on the measurement of human skin temperature. J. Therm. Biol. 2017, 69, 155-162. [CrossRef] [PubMed]

12. Moreira-Marconi, E.; Moura-Fernandes, M.C.; Lopes-Souza, P.; Teixeira-Silva, Y.; Reis-Silva, A.; Marchon, R.M.; Guedes-Aguiar, E.D.O.; Paineiras-Domingos, L.L.; Sá-Caputo, D.D.C.D.; Morel, D.S.; et al. Evaluation of the temperature of posterior lower limbs skin during the whole body vibration measured by infrared thermography: Cross-sectional study analysis using linear mixed effect model. PLOS ONE 2019, 14, e0212512. [CrossRef]

13. Marins, J.C.B.; Moreira, D.G.; Cano, S.P.; Quintana, M.S.; Soares, D.D.; Fernandes, A.D.A.; Da Silva, F.S.; Costa, C.M.A.; Amorim, P.R.D.S. Time required to stabilize thermographic images at rest. Infrared Phys. Technol. 2014, 65, 30-35. [CrossRef]

14. Fernández-Cuevas, I.; Sillero-Quintana, M.; Garcia-Concepcion, M.A.; Serrano, J.R.; Gomez-Carmona, P.; Marins, J.B. Monitoring skin thermal response to training with Infrared Thermography. New Stud. Athl. 2014, 29, 57-71.

15. Lahiri, B.; Bagavathiappan, S.; Jayakumar, T.; Philip, J. Medical applications of infrared thermography: A review. Infrared Phys. Technol. 2012, 55, 221-235. [CrossRef] [PubMed]

16. Ring, E.F.; Ammer, K. Infrared thermal imaging in medicine. Physiol Meas. 2012, 33, R33-R46. [CrossRef]

17. Fiodorenko-Dumas, Ż.; Rabczyński, M.; Paprocka-Borowicz, M.; Małecki, R.; Adamiec, R. Changes in the haemodynamics of blood flow to the lower limbs on example of thermography measurements. Acta Angiol. 2014, 2, 141-146.

18. McDivitt, J.D.; Braun, M.; Kassop, D. Cardiovascular Disease: Lower Extremity Peripheral Artery Disease. FP Essent. 2019, $479,11-15$.

19. Firnhaber, J.M.; Powell, C.S. Lower Extremity Peripheral Artery Disease: Diagnosis and Treatment. Am. Fam. Physician 2019, 99, 362-369.

20. Fiodorenko-Dumas, Ż.; Paprocka-Borowicz, M.; Dumas, I. Analiza temperatury powierzchni skóry u pacjentów z niedokrwieniem kończyn dolnych. Acta Bio-Opt. Inform. Medica 2012, 3, 177-181. 
21. Conte, M.S.; Pomposelli, F.B.; Clair, D.G.; Geraghty, P.J.; McKinsey, J.F.; Mills, J.L.; Moneta, G.L.; Murad, M.H.; Powell, R.J.; Reed, A.B.; et al. Society for Vascular Surgery practice guidelines for atherosclerotic occlusive disease of the lower extremities: Management of asymptomatic disease and claudication [published correction appears. J. Vasc. Surg. 2015, 61 (Suppl. 3), S2-S41. [CrossRef] [PubMed]

22. Jeon, C.-H.; Han, S.-H.; Chung, N.-S.; Hyun, H.-S. The validity of ankle-brachial index for the differential diagnosis of peripheral arterial disease and lumbar spinal stenosis in patients with atypical claudication. Eur. Spine J. 2011, 21, 1165-1170. [CrossRef] [PubMed]

23. Moreira, D.G.; Costello, J.T.; Brito, C.J.; Sillero-Quintana, M. A checklist for measuring skin temperature with infrared thermography in sport and exercise medicine. Thermol. Int. 2017, 27, 141-143.

24. WHO. Cardiovascular Diseases (CVDs). 2017. Available online: https://www.who.int/news-room/fact-sheets/detail/ cardiovascular-diseases-(cvds) (accessed on 24 November 2019).

25. Vilcahuaman, L.; Harba, R.; Canals, R.; Zequera, M.; Wilches, C.; Arista, M.T.; Torres, L.; Arbañil, H. Detection of diabetic foot hyperthermia by infrared imaging. In Proceedings of the 2014 36th Annual International Conference of the IEEE Engineering in Medicine and Biology Society, Chicago, IL, USA, 26-30 August 2014; pp. 4831-4834. [CrossRef]

26. Van Netten, J.J.; van Baal, J.G.; Liu, C.; van der Heijden, F.; Bus, S.A. Infrared thermal imaging for automated detection of diabetic foot complications. J. Diabetes Sci. Technol. 2013, 7, 1122-1129. [CrossRef] [PubMed]

27. Armstrong, D.G.; Holtz-Neiderer, K.; Wendel, C.; Mohler, M.J.; Kimbriel, H.R.; Lavery, L.A. Skin Temperature Monitoring Reduces the Risk for Diabetic Foot Ulceration in High-risk Patients. Am. J. Med. 2007, 120, 1042-1046. [CrossRef]

28. Lavery, L.A.; Higgins, K.R.; Lanctot, D.R.; Constantinides, G.P.; Zamorano, R.G.; Armstrong, D.G.; Athanasiou, K.A.; Agrawal, C.M. Home Monitoring of Foot Skin Temperatures to Prevent Ulceration. Diabetes Care 2004, 27, 2642-2647. [CrossRef]

29. Lavery, L.A.; Higgins, K.R.; Lanctot, D.R.; Constantinides, G.P.; Zamorano, R.G.; Athanasiou, K.A.; Armstrong, D.G.; Agrawal, C.M. Preventing Diabetic Foot Ulcer Recurrence in High-Risk Patients: Use of temperature monitoring as a self-assessment tool. Diabetes Care 2006, 30, 14-20. [CrossRef]

30. Mayrovitz, H.N.; Spagna, P.E.; Taylor, M.C. Sacral Skin Temperature Assessed by Thermal Imaging: Role of Patient Vascular Attributes. J. Wound Ostomy Cont. Nurs. 2018, 45, 17-21. [CrossRef] [PubMed]

31. Deng, F.; Tang, Q.; Jiang, M.; Zhong, N.; Liu, G. Infrared thermal imaging and Doppler vessel pressurization ultrasonography to detect lower extremity deep vein thrombosis: Diagnostic accuracy study. Clin. Respir. J. 2017, 12, 1118-1124. [CrossRef] 